\title{
NEOLIBERALISMO E SOCIEDADE JUDICIÁRIA EM FOUCAULT ${ }^{1}$
}

Thiago Mota (UECE) $)^{2,3}$

thiago.mota@uece.br

Resumo: Este artigo reconstrói a análise genealógica de Foucault acerca do neoliberalismo alemão ou ordoliberalismo, para em seguida abordar o problema da relação entre neoliberalismo e sociedade judiciária na contemporaneidade. Na sociedade neoliberal, a promoção da concorrência entre as empresas, inevitavelmente, acarreta conflitos que, em muitos casos, convertem-se em demandas judiciais. Ocorre que a concepção de que os conflitos não devem ser erradicados, mas geridos, reconvertidos em relações de concorrência e devolvidos ao mercado, tem se generalizado entre os operadores do direito. Foucault mostra que se estabelece um círculo vicioso aí: mais concorrência implica mais processos, que implicam mais concorrência, e assim por diante. A sociedade empresarial e a sociedade judiciária são os dois lados de uma mesma moeda. Daí a necessidade de se analisar tanto a judicialização da política quanto a politização do judiciário à luz da crítica genealógica ao neoliberalismo.

Palavras-chave: concorrência; conflitos; empresariamento; judicialização; ordoliberalismo.

\section{INTRODUÇÃO}

Sob vários aspectos, podemos dizer que vivemos em uma sociedade judiciária. De um lado, a quantidade de demandas judiciais é crescente e parece sempre exorbitar a

\footnotetext{
${ }^{1}$ Recebido: 24-03-2021/ Aceito: 27-09-2021/ Publicado on-line: 18-11-2021.

${ }^{2}$ É professor substituto na Universidade Estadual do Ceará, Fortaleza, CE, Brasil.

${ }^{3}$ ORCID: https://orcid.org/0000-0002-2285-5013.
} 
capacidade de provimento jurisdicional por parte do Estado, não importa que tipo de reforma institucional seja feita. De outro lado, o judiciário exerce um protagonismo sem precedentes, assumindo diretamente a tutela de questões políticas, morais, sociais e econômicas, que outrora eram prerrogativa exclusiva dos agentes legislativos e executivos. Mais do que em uma judicialização da política, fala-se em uma inédita politização do judiciário e, até mesmo, em uma ditadura judicial, cujo modus operandi seria semelhante ao de um Estado de exceção. Portanto, podemos perguntar: de onde provém a sociedade judiciária? De acordo com uma hipótese formulada por Michel Foucault (2008, p. 204), no final dos anos 1970, a sociedade judiciária é uma contrapartida direta da sociedade de empresa. $\mathrm{O}$ incentivo à concorrência e a generalização da forma-empresa geram inevitáveis conflitos, que são absorvidos na forma de litígios pelos órgãos jurisdicionais. Em outras palavras, o mercado produz os conflitos que a justiça consome: mais concorrência significa mais conflitos, que, por sua vez, significam mais processos.

Tendo em vista compreender e avaliar o alcance dessa hipótese, dividimos nossa exposição em duas partes. $\mathrm{Na}$ primeira parte, procuramos explicar o que Foucault entende por neoliberalismo. Mais especificamente, tratamos de sua análise de uma vertente do neoliberalismo, a saber, o neoliberalismo alemão ou ordoliberalismo. Na segunda parte, abordamos o problema da sociedade judiciária, em sua relação com a sociedade de empresa, na contemporaneidade. 


\section{A VIRADA NEOLIBERAL E A FENOMENOLOGIA DA CONCORRÊNCIA}

Os neoliberais alemães ou ordoliberais são críticos do liberalismo tradicional. $\mathrm{O}$ que eles buscam na economia de mercado não é apenas um princípio de limitação do poder estatal, mas um fundamento ordenador do exercício legítimo da soberania. Este não cumpre um papel meramente negativo em relação ao Estado, mas também positivo, na medida em que ordena a sua atuação. Daí a denominação “ordoliberalismo". Foucault (2008, p. 158-9) dirá que o que se busca aí não é um princípio de limitação, mas um princípio de regulação da atividade estatal como um todo. Os neoliberais alemães invertem a formula inicial do liberalismo: em lugar de um mercado sob a vigilância do Estado, eles propõem um Estado sob a vigilância do mercado. A liberdade de mercado funciona assim como um mecanismo que funda o Estado e, ao mesmo tempo, o controla. É nesse ponto que o neoliberalismo opera uma reviravolta na história do liberalismo.

Porque não há que se iludir; o neoliberalismo atual não é, de maneira nenhuma, como se diz muitas vezes, a ressurgência, a recorrência de velhas formas de economia liberal, formuladas nos séculos XVIII e XIX que o capitalismo atualmente reativaria, por certo número de razões relacionadas tanto à sua impotência, às crises que ele atravessa, quanto a certo número de objetivos políticos ou mais ou menos locais e determinados. Na verdade, o que está em questão nesse neoliberalismo atual, quer se tome a forma alemã que evoco precisamente agora, quer se tome a forma americana do anarcoliberalismo, é uma coisa muito mais importante. O que está em questão é saber se, efetivamente, uma economia de mercado pode servir de princípio, de forma e de modelo para um Estado de cujos defeitos, atualmente, a direita como a esquerda, por uma razão ou por outra, todo o mundo desconfia. (FOUCAULT, 2008, p. 159) 
Para Foucault, o neoliberalismo não é apenas uma reformulação ou uma atualização do liberalismo tradicional, ele formula algo de efetivamente novo. Mas o que há de novo no neoliberalismo? O que ainda não havia sido colocado em jogo, mas que está em jogo para ele, enfim, a novidade do neoliberalismo é a hipótese da modelização do Estado e da sociedade a partir do mercado. Em outras palavras, seu objetivo maior é a "formalização geral dos poderes do Estado e da organização da sociedade a partir de uma economia de mercado" (FOUCAULT, 2008, p. 160). A questão é saber se o mercado tem realmente essa capacidade de reformar e de enformar o Estado e a sociedade. E essa questão não é abordada pelos liberais do século XVIII, do século XIX e do início do século XX.

Essa nova questão implica uma mudança do modelo básico da relação econômica, embora nos demais aspectos a argumentação liberal tradicional seja mantida. É importante compreender, ainda que esquematicamente, esse deslocamento. Conforme Foucault (2008, p. 160-1), no antigo liberalismo, o modelo com base no qual se pensava o mercado era dado pelas relações de troca. A troca livre entre dois parceiros, vendedor e comprador, era a relação econômica fundamental e o problema essencial era estabelecer, de maneira igualitária, uma equivalência entre o valor faturado com a venda e o valor despendido com a compra. No final da transação, a soma deveria ser nula. O Estado, que deveria se manter à distância da circulação, supervisionava a produção, mas apenas para garantir que os produtores gozariam com segurança da propriedade do que houvessem produzido. Por outro lado, para o novo liberalismo, o mo- 
delo da relação econômica não vai ser a troca, mas a concorrência. $\mathrm{O}$ que fornece a fórmula da atividade econômica é a relação entre competidores em um jogo concorrencial cujo resultado deve ser desigual. Com isso, o problema deixa de ser como estabelecer uma equivalência entre os valores ganho e pago, e passa a ser como promover a concorrência e como evitar o monopólio. A racionalidade econômica passa a estar assentada no princípio da concorrência, que regula espontaneamente, por meio do mecanismo de preços, as escolhas dos agentes econômicos e, por conseguinte, a distribuição das riquezas, que pode ou não ser igualitária.

Foucault (2008, p. 162) entende que o ordoliberalismo também implica um deslocamento em relação a uma outra corrente do liberalismo que é composta pelo marginalismo do século XIX e pelo neomarginalismo do início do século XX. Os marginalistas defendem que o mercado só pode funcionar adequadamente se for mantido absolutamente livre para que a concorrência seja plena. O Estado deve se abster totalmente de qualquer intervenção que possa modificar a situação espontânea de concorrência e, sobretudo, não deve introduzir monopólios estatais no mercado, nem tampouco controlar setores da economia. No máximo, o que o Estado deve fazer é evitar que se formem monopólios privados, para que a situação de plena concorrência não seja modificada. Mais radicais, os neomarginalistas sustentam um anarcocapitalismo em conformidade com o qual o Estado nem sequer deveria existir. Em todo caso, a conclusão a que chegam marginalistas e neomarginalistas não se distingue daquela a que chegavam os liberais do século XVIII, ou seja, a ideia de que o princípio da economia é o laissez- 
faire. Assim, juntamente com o liberalismo clássico, o marginalismo e o neomarginalismo integram a grande corrente do capitalismo laissez-faire. A diferença entre eles está apenas no seguinte: se o liberalismo clássico deduz do laissez-faire a relação de troca, o marginalismo extraí desse mesmo princípio a relação de concorrência.

É nesse ponto que os ordoliberais rompem com a tradição do liberalismo. Para eles, nem a relação de troca, nem a relação de concorrência podem ser deduzidas do laissez-faire. Os liberais tradicionais concebem a concorrência e, por conseguinte, o mercado como um dado natural, algo que se produz espontaneamente e que não deve sofrer nenhuma interferência de ordem política. Ora, para os ordoliberais isso significa incorrer em uma falácia naturalista. É aí que se pode perceber claramente a influência exercida pela fenomenologia de Husserl sobre o ordoliberalismo.

Pois, de fato, o que é a concorrência? Não é de modo algum um dado natural. A concorrência, em seu jogo, em seus mecanismos e em seus efeitos positivos que identificamos e valorizamos, não é em absoluto um fenômeno natural, não é o resultado de um jogo natural dos apetites, dos instintos, dos comportamentos, etc. Na realidade, a concorrência não deve seus efeitos senão a essência que ela detém, que a caracteriza e a constitui. A concorrência não deve seus efeitos benéficos a uma anterioridade natural, a um dado natural que ela traria consigo. Ela os deve a um privilégio formal. Pois, de fato, o que é a concorrência? Não é de modo algum um dado natural. A concorrência é uma essência. Pois, de fato, o que é a concorrência? Não é de modo algum um dado natural. A concorrência é um eidos. A concorrência é um princípio de formalização. A concorrência possui uma lógica interna, tem sua estrutura própria. Seus efeitos só se produzem se essa lógica é respeitada. É, de certo modo, um jogo formal entre desigualdades. Não é um jogo natural entre indivíduos e comportamentos. (FOUCAULT, 2008, p. 163) 
Os ordoliberais vão abordar a concorrência como um "fenômeno", no sentido da fenomenologia. Ela não será concebida como um dado natural bruto, mas como uma essência, como um eidos. Ela será um princípio formal, com sua lógica e estrutura próprias. Por certo, ela será um jogo, mas um jogo formal. Há uma epoché neoliberal, que suspende precisamente o dado econômico natural, para chegar à intuição pura da concorrência em sua essência. Dessa maneira, a lógica econômica só pode se manifestar no fenômeno da concorrência se as condições dessa intuição da espontaneidade econômica forem prévia e artificialmente preparadas. A concorrência não é um ponto de partida, mas um alvo a ser alcançado, o que demanda uma ação política ilimitada. Ela não é um dado natural, mas um objetivo histórico a ser construído pela arte neoliberal de governar. Para Foucault (2008, p. 164), aí se encontra um ponto de cruzamento entre a fenomenologia de Husserl e a sociologia de Weber no seio da ciência econômica. Ou seja, na concepção ordoliberal, o saber econômico nasce do cruzamento entre uma análise histórica dos processos econômicos e uma análise formal da estrutura desses mesmos processos. Nessa perspectiva, a concorrência só vai aparecer em sua pureza como uma essência, se as condições de possibilidade para isso forem previamente construídas por uma prática governamental ativa. Portanto, o mercado totaliza a racionalidade governamental e a concorrência se universaliza. Estamos diante de uma governamentalidade de mercado que faz da concorrência o indexador básico de sua própria atuação. 
Vai-se ter portanto uma espécie de justaposição total dos mecanismos de mercado indexados à concorrência e da política governamental. O governo deve acompanhar de ponta a ponta uma economia de mercado. A economia de mercado não subtrai algo do governo. Ao contrário, ela indica, ela constitui o indexador geral sob o qual se deve colocar a regra que vai definir todas as ações governamentais. (FOUCAULT, 2008, p. 165).

Com isso, tocamos novamente na questão do direito, ou ainda, começamos a visualizar o papel que ele vai cumprir na governamentalidade ordoliberal. $O$ direito será essa "regra" que possibilitará e condicionará o agenciamento entre a economia de mercado e a racionalidade governamental. Uma vez que é formal, o princípio da concorrência é eficiente no que diz respeito a fornecer um modelo para a análise das relações econômicas, mas ele não é diretamente aplicável à realidade social. Para isso, será necessário que se coloque sob ele uma "regra”, isto é, uma norma jurídica, uma lei que o positive. Para se realizar na história, o princípio da concorrência precisará ser convertido em um princípio de direito positivo que possibilitará a indexação, pela concorrência, de toda prática de governo. $\mathrm{O}$ direito surge como a concretização, no plano normativo institucional, dos princípios pura da economia de mercado.

Nesse contexto, Foucault (2008, p. 179-81) discute a inutilidade para o presente das críticas que não identificam as especificidades do neoliberalismo. São leituras econômicas, políticas ou sociológicas para as quais o neoliberalismo ou é apenas uma reformulação da doutrina econômica do liberalismo tradicional, ou é um mero disfarce para um Estado hiper-administrativo, ou é estritamente a mercantilização das relações sociais. Ora, essas leituras "fazem o neoliberalismo aparecer como não sendo, afinal de contas, 
absolutamente nada" (FOUCAULT, 2008, p. 180). Isso é, aliás, o que defendem os que negam a existência do neoliberalismo (SARDENBERG, 2008). Foucault (2008, p. 181), ao contrário, insiste no problema do neoliberalismo "para tentar separá-lo das críticas que são feitas a partir de matrizes históricas pura e simplesmente transpostas. O neoliberalismo não é Adam Smith; o neoliberalismo não é a sociedade mercantil; o neoliberalismo não é o Gulag na escala insidiosa do capitalismo". Tampouco é a sociedade de consumo ou a sociedade do espetáculo. A especificidade do neoliberalismo é que seu problema é "saber como se pode regular o exercício global do poder político com base nos princípios de uma economia de mercado" (FOUCAULT, 2008, p. 181), ou seja, na concorrência. Se, para o liberalismo do século XVIII, o problema era garantir um espaço livre para o mercado em uma sociedade já organizada politicamente, para o ordoliberalismo, o problema será estabelecer a relação entre os princípios formais do mercado e a prática governamental numa situação em que os aparelhos administrativos e judiciários ainda se encontram em construção.

Tendo isso em vista, a arte de governar neoliberal vai promover certas modificações no modo de pensar do liberalismo clássico. Em primeiro lugar, os ordoliberais vão dissociar a economia de mercado do princípio do laissez-faire, na medida em que concebem este como um dado de natureza e aquela como baseada no princípio puro, formal da concorrência, obtido artificialmente, via redução eidética. Assim, o problema da política neoliberal não é simplesmente deixar o mercado funcionar, mas organizar o espaço real em que a concorrência plena possa se desenrolar. "O neolibera- 
lismo não vai portanto se situar sob o signo do laissez-faire, mas, ao contrário, sob o signo de uma vigilância, de uma forma de atividade, de uma intervenção permanente" (FOUCAULT, 2008, p. 182).

Em segundo lugar, os ordoliberais introduzem uma distinção importante entre ações reguladoras e ações ordenadoras. Foucault (2008, p. 189) esclarece que, de um lado, as ações reguladoras se configuram como um tipo de intervenção estatal que não incide nos mecanismos do mercado, mas que reconhece, favorece, deixa agir as tendências naturais da economia. Em outras palavras, a ação reguladora do Estado apenas reflete ou mimetiza a atividade autorregulada do mercado. Assim, a ação governamental reguladora não tem como finalidade maior a manutenção do poder aquisitivo, nem o pleno emprego, nem mesmo o equilíbrio entre importações e exportações. Todos esses são objetivos secundários em relação ao objetivo principal que é puramente econômico, ou seja, a estabilidade dos preços, a contenção da inflação. Em todo caso, esse tipo de ação já era praticado no contexto do liberalismo tradicional.

De outro lado, estão as ações que o liberalismo clássico não costumava desempenhar, isto é, as ações ordenadoras que incidem especificamente nas condições de existência do mercado, especificamente, sobre o que Foucault (2008, p. 192) chama de "moldura" (cadre). Temos, portanto, uma "política de moldura". Essa moldura é constituída por elementos como: a população, cujo número pode variar; as tecnologias à disposição para o desenvolvimento da atividade produtiva; o nível educacional dos trabalhadores, sua formação, grau de ensino; a legislação, o regime jurídico da propriedade que também se altera ao longo do tempo; os 
recursos naturais, qualidade dos solos clima etc. Cabe observar que nenhum desses fatores é, propriamente falando, de ordem econômica, mas suas oscilações têm impacto macroeconômico quase imediato. Para Eucken, o problema será, então: como mudar as fundações não apenas materiais, mas também técnicas, culturais e jurídicas, ou seja, como modificar a moldura institucional de modo a fazer com que a autorregulação mercantil funcione? Como alterar essa moldura para que a economia opere livremente? As ações ordenadoras são, portanto, ações de ordenação voltadas para a criação uma ordem concorrencial de mercado, ou ainda, de uma ordem liberal, donde "ordoliberalismo". Assim,

[...] tanto a intervenção governamental deve ser discreta no nível dos processos econômicos propriamente ditos, como, ao contrário, deve ser maciça quando se trata desse conjunto de dados técnicos, científicos, jurídicos, demográficos, digamos, grosso modo, sociais, que vão se tornar agora cada vez mais o objeto da intervenção governamental. (FOUCAULT, 2008, p. 194).

De um lado, menos intervenção econômica, de outro, mais intervenção na moldura institucional. Isso significa que a incidência das políticas governamentais, por exemplo, sobre o campo do direito deve crescer, ao mesmo tempo em que sua incidência sobre o plano da economia deve diminuir. Entretanto, o aumento da importância do campo jurídico não se dá de maneira isolada, mas em conexão com o reforço de uma série de outros campos de diferentes ordens. Considerada em seu conjunto, é essa rede de tecnologias judiciárias e para-judiciárias que compõe a racionalidade governamental neoliberal. A tecnologia jurídica vem se situar em um cruzamento om várias outras tecnologias, na moldura governamental de uma economia de 
mercado.

Contudo, o neoliberalismo também se diferencia do liberalismo de tipo keynesiano. De acordo com Foucault (2008, p. 194-5), a diferença pode ser claramente percebida no que concerne à política social. Em uma economia de bem-estar social, a igualdade econômica é tomada como um objetivo político de primeira ordem, de modo que a política social venha a compensar os efeitos de desigualdade social produzidos pelos processos econômicos. Ela constitui, assim, uma espécie de contraponto ao que acontece no plano econômico. Isso implica uma socialização de itens essenciais de consumo, tais como saúde, habitação, educação, cultura, lazer etc., que se realiza por meio de programas de redistribuição de renda, de subsídios à família, de assistência médica gratuita, de financiamento estudantil etc. Desse modo, em um Estado de bem-estar social, em princípio, à medida que a economia cresce, também se ampliam os programas sociais e os processos de distribuição de riqueza. $\mathrm{O}$ crescimento econômico significa, de imediato, mais igualdade relativa e, no longo prazo, igualdade plena.

$\mathrm{O}$ ordoliberalismo reage a isso ponto por ponto. Em primeiro lugar, seus representantes entendem que a redução da desigualdade não pode ser um objetivo político. Ao invés de tomar a igualdade como meta, a política social deve deixar a desigualdade agir, pois "o jogo econômico, com os efeitos desigualitários que ele comporta, é uma espécie de regulador geral da sociedade [...] Logo, nada de igualização e, por conseguinte, de modo mais preciso, nada de transferência de renda" (FOUCAULT, 2008, p. 196). Nessas condições, a desigualdade é igual para todos e pode cumprir um papel positivo em relação ao desenvolvimento 
do mercado e, por conseguinte, da sociedade.

Em segundo lugar, ao invés de uma socialização da renda e do consumo, o que vai haver é a privatização. A política social não funcionará com base em mecanismos de transferência de riqueza, mas através da capitalização dos indivíduos, da privatização da previdência e da seguridade e do reforço ao regime jurídico da propriedade privada. Temos aí uma distinção entre uma política social individualizante, que os ordoliberais defendem, e uma política social socializante, que eles rejeitam. "Trata-se de uma individualização da política social, uma individualização pela política social em vez de ser essa coletivização e essa socialização por e na política social" (FOUCAULT, 2008, p. 197). Portanto, na medida em que o neoliberalismo não pretende ter um efeito massificador, ele utiliza a política social para individualizar e para possibilitar que a produção e a reprodução dos indivíduos ocorra de maneira regulada. É paradoxal, mas não ineficaz.

Em terceiro lugar, para o ordoliberalismo a única política social a ser adotada é crescimento econômico que, se for elevado o bastante, possibilitará que todos alcancem um nível de renda mínimo. Com isso, o custo social que era assumido pelo Estado de bem-estar pode ser revertido para os indivíduos. A ideia é que com a redução do peso do Estado, o chamado ajuste das contas públicas, a economia poderá crescer. Aliás, segundo Foucault (2008, p. 198), o anarcocapitalismo norte-americano se desenvolve, precisamente, a partir dessa recusa à política social, que eles consideram socialista ou intervencionista. A ela, os anarcocapitalistas vão opor uma política social privada, que era a tendência dominante no tempo de Foucault e é, ainda mais, nos dias 
atuais.

Em resumo, a desigualdade como mecanismo de regulação social, a privatização do custo social da manutenção e do desenvolvimento da sociedade e o crescimento econômico como política social exclusiva: podemos dizer que essas são três características que opõem o neoliberalismo, tanto alemão quanto norte-americano, ao liberalismo keynesiano.

\section{BIOPOLÍTICA, EMPRESARIAMENTO E SOCIEDADE JUDICIÁRIA}

Se o liberalismo intervencionista defende a necessidade de uma política ou de um governo social, o neoliberalismo formulará a ideia de um governo ou de uma política de sociedade. Temos aqui de um tipo específico de biopolítica (Biopolitik), a sociopolítica (Sozialpolitik), ou ainda, a política de sociedade (Gesellschaftspolitik). Com isso, o neoliberalismo efetua um importante deslocamento do ponto de aplicação da intervenção governamental. Esse ponto de aplicação que, como para o liberalismo clássico, não é o mercado, agora também deixa de ser o Estado e passa a ser, diretamente, a sociedade. Assim, para os ordoliberais, o governo

[...] tem de intervir sobre a própria sociedade em sua trama e em sua espessura. No fundo, ele tem de intervir nessa sociedade para que os mecanismos concorrenciais, a cada instante e em cada ponto da espessura social, possam ter o papel de reguladores - e é nisso que a sua intervenção vai possibilitar o que é o seu objetivo: a constituição de um regulador de mercado geral da sociedade. Vai se tratar portanto, não de um governo econômico [...], isto é, o governo tem apenas de reconhecer e observar as leis econômicas; não é um go- 
verno econômico, é um governo de sociedade. (FOUCAULT, 2008, p. 199).

O que está em jogo (enjeu) na política de sociedade dos neoliberais alemães é a própria sociedade, ela é o alvo das ações de governo. Aí se encontra claramente o ponto de ruptura do neoliberalismo em relação ao liberalismo tradicional. Não se trata de limitar o Estado, nem muito menos de intervir no mercado. Todavia, se não se trata de governar a economia, tampouco será a população o objeto do governo. A arte neoliberal de governar se distingue do Estado de polícia, instaurando uma nova perspectiva de exercício da biopolítica, na medida em que define para si um outro objeto. Ela visa governar a sociedade, ou ainda, regular aquilo que os ordoliberais chamam, empregando uma terminologia extraída da fenomenologia, de mundo-ambiente social (soziale Umwelt). Daí a ideia econômico-fenomenológica da biopolítica (Biopolitik), entendida como uma política de mundo-ambiente (Umweltpolitik).

Segundo Foucault (2008, p. 330), tendo a sociedade como campo de incidência, os ordoliberais definirão como objetivo geral das práticas governamentais fazer do mercado o princípio regulador da sociedade. Para isso, será preciso implantar uma política de sociedade que seja efetivamente capaz de organizá-la, abrindo espaço para que os mecanismos de concorrência ajam de maneira livre e espontânea. De maneira mais concreta, trata-se, para os ordoliberais, de realizar um certo número de objetivos no que concerne à regulação dos problemas relativos ao ambiente circundante do mercado, tais como evitar a centralização, favorecer empresas pequenas e médias, ampliar o acesso à propriedade 
etc. Com efeito, a política de sociedade propõe uma quantidade imensa de intervenções governamentais, o que, por sinal, revela um paradoxo, digamos, político-econômico. De um lado, os ordoliberais defendem o princípio da não intervenção no mercado, mas em prol mercado, porém, de outro lado, eles propõem uma quantidade de tipos de intervenção que, à luz desse mesmo princípio, parece abusiva. Cabe observar que esse paradoxo político-econômico será objeto de críticas feitas ao ordoliberalismo pelos neoliberais norte-americanos, nos anos 1960 e 1970.

Ocorre que regular pelo mercado ou em prol do mercado não é o mesmo que disciplinar ou normalizar a partir da forma-mercadoria. O neoliberalismo não significa a mercantilização integral da sociedade, sua formalização geral de acordo com o modelo geral das relações de troca. Ele tampouco significa a reificação global por meio da universalização da forma-salário, que possibilita a conversão integral do tempo de vida em força de trabalho. Com efeito, o neoliberalismo alemão é consciente e crítico em relação aos efeitos de massificação decorrentes da mercantilização da sociedade e se opõe às suas diferentes estratégias uniformizadoras: a sociedade de consumo, a sociedade unidimensional, a sociedade de espetáculo, a sociedade dos simulacros (BAUDRILLARD, 1991), a sociedade da velocidade (VIRILIO, 1996) etc. Em suma, o neoliberalismo é uma racionalidade de governo crítica da uniformização da sociedade e, em oposição a ela, ele procura pensar a realidade social a partir da multiplicidade e da diferenciação das unidades produtivas, definindo essas como empresas.

A sociedade regulada com base no mercado em que pensam os neo- 
liberais é uma sociedade na qual o que deve constituir o princípio regulador não é tanto a troca das mercadorias quanto os mecanismos da concorrência. São esses mecanismos que devem ter o máximo de superfície e de espessura possível, que também devem ocupar o maior volume possível na sociedade. Vale dizer que o que se procura obter não é uma sociedade submetida ao efeito-mercadoria, é uma sociedade submetida à dinâmica concorrencial. Não uma sociedade de supermercado - uma sociedade empresarial. (FOUCAULT, 2008, p. 201).

Consequentemente, neoliberalismo não significa mercantilização, mas empresariamento da sociedade. Ele é sua modelização geral em conformidade com a forma-empresa. Para ele, não se trata de pensar a sociedade com base na relação de troca entre produtores e consumidores, mas de pensá-la a partir de relações de concorrência, tais como as que se estabelecem entre empresários que competem entre si por um objetivo que é universalmente compartilhado: o lucro. Assim, o que os ordoliberais têm em vista não é uma sociedade mercantil, mas sim uma sociedade de empresa (société d'entreprise) que, desse modo, aparece como uma utopia neoliberal. Entretanto, eles sustentam que essa sociedade de empresa não se produz sem que uma política de sociedade seja implantada. Nesse sentido, uma política de sociedade quer dizer

[...] generalizar de fato a forma "empresa" no interior do corpo ou do tecido social; quer dizer, retomar esse tecido social e fazer que ele possa se repartir, se dividir, se desdobrar, não segundo o grão dos indivíduos, mas segundo o grão da empresa. A vida do indivíduo não tem de se inscrever como vida individual num âmbito de grande empresa, que seria a firma ou, no limite, o Estado, mas tem de poder se inscrever no âmbito de uma multiplicidade de empresas diversas encaixadas e entrelaçadas, de empresas que estão, para o indivíduo, de certo modo ao alcance da mão, bastante limitadas em seu tama- 
nho para que a ação do indivíduo, suas decisões, suas opções possam ter efeitos significativos e perceptíveis, bastante numerosas também para que ele não fique dependente de uma só; e, enfim, a própria vida do indivíduo - com, por exemplo, sua relação com a sua propriedade privada, sua relação com a sua família, com o seu casamento, com os seus seguros, com a sua aposentadoria - tem de fazer dele como que uma espécie de empresa permanente e de empresa múltipla. É portanto essa reenformação da sociedade segundo o modelo da empresa, das empresas, e isso até no seu grão mais fino, é isso que é um aspecto da Gesellschaftspolitik dos ordoliberais alemães. Ora, que função tem essa generalização da forma "empresa"? Por um lado, claro, trata-se de desdobrar o modelo econômico, o modelo oferta e procura, o modelo investimento-custo-lucro, para dele fazer um modelo das relações sociais, um modelo da existência, uma forma de relação do indivíduo consigo mesmo, com o tempo, com seu círculo, com o futuro, com o grupo, com a família. Desdobrar esse modelo econômico, é verdade. E, por outro lado, essa ideia dos ordoliberais de fazer da empresa, assim, o modelo social universalmente generalizado serve de suporte, em sua análise e em sua programação, para o que e designado por eles como a reconstituição de toda uma série de valores morais e culturais que poderíamos chamar de valores "quentes" e que se apresentam justamente como antitéticos do mecanismo "frio" da concorrência. (FOUCAULT, 2008, p. 331-2).

A generalização da forma-empresa operada pelos ordoliberais significa que o neoliberalismo não implica um simples retorno do laissez-faire nem da sociedade mercantil, mas uma descoberta da ética social da empresa, ou ainda, a percepção da existência de um ethos empresarial (SENNETT, 2006), de uma espécie de moral consuetudinária dos negócios, ou ainda, de uma "cultura empreendedorismo" (GADELHA, 2009), em cujos valores se baseia o processo espontâneo de subjetivação dos agentes econômicos. O ambiente de trabalho não é concebido como lugar em que ocorre um processo de alienação do trabalhador, mas como um meio em que o sujeito adquire os valores que devem 
orientá-lo em sua prática profissional e também em sua vida privada, na relação com amigos e familiares, bem como na relação que o sujeito estabelece consigo próprio e na maneira como ele coloca o problema do sentido de sua própria existência.

Assim, o homo œconomicus não será mais concebido, à maneira do liberalismo clássico, como o sujeito da relação de troca, mas como o empresário. Para os ordoliberais, é do ethos empresarial que as premissas da ação governamental devem ser extraídas. É esse "direito natural econômico" que deve funcionar como princípio geral de programação das práticas governamentais. Logo, para racionalizar a atuação do governo, não se trata de partir de cima (top down), isto é, daqueles que exercem o poder soberano, dos governantes, mas de baixo (bottom up), dos governados, de suas práticas, costumes e hábitos, em uma palavra, do ethos dos indivíduos e dos grupos em suas relações naturais de concorrência. A crença básica é a de que o homem é um competidor por natureza. Foucault (2008, p. 202) menciona um termo que o economista Alexander Rüstow ${ }^{4}$, da Escola de Freiburg, utiliza para se referir a isso: Vitalpolitik, literalmente, a política da vida. Com efeito, não estamos mais simplesmente diante de uma espécie de biopolítica, como no caso da política de sociedade (Gesellschaftspolitik). O que temos aqui é a própria biopolítica (Biopolitik), a política vital. Ora, nessa Vitalpolitik, trata-se de

\footnotetext{
${ }^{4}$ Alexander Rüstow (1885-1963) foi um economista e sociólogo alemão, considerado um dos referenciais fundamentais da Escola Ordoliberal. Cunhou o termo "neoliberalismo", durante o colóquio Walter Lippmann (1938).(RÜSTOW, 2001)
} 
[...] constituir uma trama social na qual as unidades de base teriam precisamente a forma da empresa, porque o que é a propriedade privada, senão uma empresa? O que é uma casa individual, senão uma empresa? O que é a gestão dessas pequenas comunidades de vizinhança senão outras formas de empresa? Em outras palavras, trata-se de generalizar, difundindo-as e multiplicando-as na medida do possível, as formas "empresa" que não devem, justamente, ser concentradas na forma nem das grandes empresas de escala nacional ou internacional, nem tampouco das grandes empresas do tipo do Estado. É essa multiplicação da forma "empresa" no interior do corpo social que constitui, a meu ver, o escopo da política neoliberal. Trata-se de fazer do mercado, da concorrência e, por conseguinte, da empresa o que poderíamos chamar de poder enformador da sociedade. (FOUCAULT, 2008, p. 203).

$\mathrm{Na}$ racionalidade governamental ordoliberal, o mercado é e deve ser um poder de enformar, de pôr na fôrma e, portanto, de dar forma, de formatar, de formalizar a sociedade. Trata-se de uma política de economicização de todo o campo social, individual e até mesmo existencial. Seu princípio é a concorrência e seu modus operandi é o empresariamento da vida social desde suas unidades básicas, ou seja, é a modelização dos hábitos dos indivíduos e dos costumes dos grupos, segundo os contornos da forma-empresa. É isso a política de sociedade, a Vitalpolitik, o neoliberalismo.

Todavia, ainda há o aspecto jurídico dessa discussão. Por certo, a arte de governar neoliberal implica uma modificação radical não só do sistema das leis e da configuração geral do ordenamento jurídico, mas também do papel das práticas e das instituições jurisdicionais. Não é à toa que, em uma sociedade formalizada pelo modelo da empresa, a jurisdição se torna a função estatal mais importante. Com o empresariamento generalizado, há necessariamente uma judicialização da política que pode, em circunstâncias extre- 
mas, chegar a uma politização do judiciário. Embora esses termos sejam um tanto confusos, o raciocínio não é complicado:

Quanto mais você multiplica a empresa, quanto mais você multiplica as empresas, quanto mais você multiplica os centros de formação de uma coisa como uma empresa, quanto mais você força a ação governamental a deixar essas empresas agirem, mais, é claro, você multiplica as superfícies de atrito entre cada uma dessas empresas, mais você multiplica as ocasiões de contenciosos, mais você multiplica também a necessidade de uma arbitragem jurídica. Sociedade empresarial e sociedade judiciária, sociedade indexada à empresa e sociedade enquadrada por uma multiplicidade de instituições judiciárias são as duas faces de um mesmo fenômeno. (FOUCAULT, 2008, p. 204).

incentivo à concorrência acarreta a elevação do número de conflitos e disso decorre o crescimento da demanda judiciária. Ora, a interpretação e a aplicação do direito devem ser orientadas para a obtenção de soluções que restaurem a situação normal de concorrência. Essa, porém, gera inevitavelmente novos conflitos e, por conseguinte, novas demandas por tutela jurisdicional. É um circuito que se estabelece aí: sociedade de empresa produz os conflitos que a sociedade judiciária consome; esta os regulariza e os devolve para o mercado, que produz novos conflitos e assim por diante. Sociedade empresarial e sociedade judiciária são os dois lados de uma só moeda e, como tal, devem funcionar em sincronia. Isso não implica buscar dirimir os conflitos que surgem no seio da sociedade definitivamente ou eliminá-los em sua mera possibilidade. Trata-se de geri-los para que se mantenham em um nível que não comprometa as condições de governo, ou seja, que não atrapalhe o fun- 
cionamento natural do mercado. Não se trata tanto da solução dos conflitos quanto de sua gestão.

Assim, aquele que é considerado o maior problema do poder judiciário na contemporaneidade (CAPPELLETTI; GARTH, 1988), isto é, o excesso da quantidade de processos que acarreta a morosidade na finalização dos julgamentos, revela-se como algo que não é realmente tão problemático. Como os conflitos são parte da dinâmica de uma sociedade concorrencial, a lentidão da Justiça não é propriamente um problema, mas parte da solução. Ela integra uma estratégia global de manutenção dos conflitos em um patamar governável, isto é, uma estratégia de conversão, sempre instável e precária, dos conflitos sociais em relações de concorrência, por meio de procedimentos de regularização jurídica. Eis uma definição ordoliberal de processo judicial. A análise genealógica mostra que, assim como o hospício não tem por finalidade a cura dos loucos e a prisão não objetiva eliminar os delinquentes (FOUCAULT, 1997, p. 79-86), a jurisdição não deve procurar erradicar os conflitos, mas produzi-los de maneira regulada, geri-los a fim de normalizá-los, em uma palavra, governá-los. Portanto, para os neoliberais, trata-se de reconhecer que os conflitos são parte da vida de uma sociedade fundada no mecanismo da concorrência e que é como tal que eles devem ser governados. A jurisdição é o governo dos conflitos, e não sua solução.

Também podemos ver nesse ponto a novidade do neoliberalismo, em comparação ao liberalismo clássico. Na medida em que fazia a defesa do governo da lei contra o arbítrio dos déspotas, o liberalismo do século XVIII reduzia a importância das formas jurídicas, judiciárias ou jurispru- 
denciais de governo. Em conformidade com o princípio liberal da separação dos poderes, o judiciário devia se restringir à aplicação de uma lei que ele mesmo, por definição, não podia estabelecer. Tratava-se, portanto, de dividir claramente e, até mesmo, de opor a função legislativa à função jurisdicional. Era preciso assegurar a primazia do poder democrático dos legisladores sobre o poder soberano dos juízes.

Segundo Foucault (2008, p. 240), no neoliberalismo, o judiciário é revalorizado e se torna mais independente em relação aos outros poderes, chegando até mesmo a substituílos, sob certos aspectos, em suas funções específicas. A sociedade neoliberal incentiva a multiplicação das empresas e de suas dinâmicas. Ora, isso implica a propagação das situações de conflito que, por sua vez, significa o aumento do número de litígios levados à apreciação dos órgãos jurisdicionais. Temos aí o fenômeno da inflação processual, isto é, ampliação da quantidade de processos a serem julgados. $\mathrm{O}$ aparelho judiciário é abarrotado, o processamento dos feitos trava. Torna-se, então, necessário criar outras instâncias jurisdicionais e novas práticas de provimento do direito. Em síntese, multiplicam-se as empresas, multiplicam-se os conflitos, multiplicam-se os juízes.

Enquanto a regulação econômica se dá espontaneamente, pelas propriedades formais da concorrência, a regulação social por sua vez - a regulação social dos conflitos, das irregularidades de comportamento, dos danos provocados por uns aos outros, etc. - tudo isso vai exigir um intervencionismo, um intervencionismo judiciário, que deverá ser praticado como arbitragem no âmbito das regras do jogo. Multipliquem as empresas, e multiplicarão os atritos, os efeitos de ambiente, e, por conseguinte, à medida que vocês libertarem os sujeitos econômicos e deixarem que eles joguem seu jogo, quanto mais 
os libertarem, mais, ao mesmo tempo, vocês os destacarão do estatuto de funcionários virtuais a que um plano os prendia e mais multiplicarão necessariamente os juízes. Menos funcionários, ou antes, desfuncionalização dessa ação econômica que os planos traziam consigo, multiplicação da dinâmica das empresas e, com isso, necessidade de instâncias judiciárias ou, em todo caso, de instâncias de arbitragem cada vez mais numerosas. (FOUCAULT, 2008, p. 240-1).

Assim, ao lado da regulação econômica espontânea pelo princípio da concorrência, a sociedade neoliberal necessita de uma regulação jurídica, ou ainda, de um intervencionismo judiciário. Além de um maior protagonismo dos juízes, ou seja, do ativismo judicial (CAPPELLETTI, 1993), o intervencionismo judiciário também significa a multiplicação e a diversificação dos procedimentos jurisdicionais (FUX, 2014). Surgem novas técnicas de solução de conflitos, mecanismos de autotutela são redescobertos, métodos alternativos que prescindem da organização judiciária do velho Estado são criados, tais como a conciliação, a mediação e a arbitragem extrajudiciais ${ }^{5}$. De modo geral, verifica-se uma externalização, ainda que parcial, da função jurisdicional, ou ainda, uma privatização da jurisdição, que deixa de ser exercida exclusivamente pelo poder público e passa a ser explorada também por empresas do setor privado como atividade lucrativa. De um lado, multiplicam-se as instituições encarregadas do exercício da

\footnotetext{
${ }^{5}$ Essa tendência pode ser verificada nos parágrafos do art. 3o do novo Código de Processo Civil brasileiro: "§ $1^{\circ}$ É permitida a arbitragem, na forma da lei. $\S 2^{\circ} \mathrm{O}$ Estado promoverá, sempre que possível, a solução consensual dos conflitos. $\S 3^{\circ}$ A conciliação, a mediação e outros métodos de solução consensual de conflitos deverão ser estimulados por juízes, advogados, defensores públicos e membros do Ministério Público, inclusive no curso do processo judicial”. Cf. BRASIL. Lei n. 13.105, de 16 de março de 2015. Código de Processo Civil. Disponível em: <http://www.planalto.gov.br/ccivil 03/ ato2015-2018/2015/lei/113105.htm>. Acesso em: 20 set. 2020.
} 
função jurisdicional no interior do aparelho de Estado, por meio da criação de tribunais administrativos vinculados ao poder executivo. De outro lado, propaga-se o surgimento de tribunais arbitrais privados, que se posicionam no exterior da estrutura do Estado. A tecnologia jurídica ganha uma série de novos aparelhos e se expande de maneira inédita.

Em todo caso, essas instâncias judiciárias, administrativas e arbitrais exercem, em conjunto, uma função econômica. Elas não devem funcionar simplesmente como órgãos judiciários, mas como órgãos jurisdicionais da economia, responsáveis por dizer o direito econômico. Na medida do possível, é essa estrutura, constituída por pessoal técnico especializado e diversificado, que deve substituir a atuação das autoridades políticas e administrativas. Em nome da eficiência e da agilidade, procura-se deixar para trás a rígida burocracia estatal. O resultado é uma judicialização sem precedentes de questões que outrora diziam respeito somente à política e à administração (BARROSO, 2012). A judicialização tende a não ser mais entendida como uma situação extraordinária, tende a se tornar o processamento regular para esse tipo de questão e, portanto, a ser a forma ordinária de regulação normalizadora dos conflitos sociais. Em suma, ao mesmo tempo em que a intervenção administrativa mingua, a intervenção judiciária se agiganta. $O$ liberalismo político-econômico tem como correlato o intervencionismo jurisdicional, a sociedade empresarial também é a sociedade judiciária.

Abstract: This article reconstructs Foucault's genealogical analysis of German neoliberalism or ordoliberalism, in order to then address the problem of the relationship between neoliberalism and judiciary society in contemporary times. In neoliberal society, the promotion of competition between corporations inevitably leads to conflicts that, in many cases, turn into judicial 
demands. Now, the conception that conflicts should not be eradicated, but managed, converted into competitive relations and returned to the market, has become widespread among law operators. Foucault shows that a vicious circle is established there: more competition implies more processes, which implies more competition, and so on. The business society and the judiciary society are two sides of a same coin. Hence the need to analyze both the judicialization of politics and the politicization of the judiciary in the light of the genealogical critique of neoliberalism.

Key-words: competition; conflicts; entrepreneurship; judicialization; ordoliberalism.

\section{REFERÊNCIAS}

BARROSO, L. R. Judicialização, ativismo judicial e legitimidade democrática. [Synue]Thesis, Rio de Janeiro, v. 5, n. 1, pp. 23-32, 2012. Disponível em: <http://www.epublica-

coes.uerj.br/index.php/synthesis/article/view/7433/5388 > Acesso em: 20 set. 2020.

BAUDRILLARD, J. Simulacros e simulação. Tradução de M. Pereira. Lisboa: Relógio d'Água, 1991.

BRASIL.Lei n. 13.105. Código de Processo Civil. 2015.Disponível em:

<http://www.planalto.gov.br/ccivil 03/ ato20152018/2015/lei/113105.htm>. Acesso em: 20 set. 2020.

CAPPELLETTI, M. Juízes legisladores? Tradução: A. Oliveira. Porto Alegre: Sérgio Antonio Fabris Ed.,1993.

CAPPELLETTI, M; GARTH, B. Acesso à justiça. Tradução de E. Northfleet. Porto Alegre: Sérgio Antonio Fabris Ed., 1988.

FOUCAULT, M. Nascimento da biopolítica: curso dado 
no Collège de France (1978-1979). Tradução: E. Brandão. São Paulo: Martins Fontes,2008.

- Vigiar e punir: nascimento da prisão. Tradução de R. Ramalhete. 16.ed. Petrópolis: Vozes, 1997.

FUX, L.O novo processo civil. Revista do TST, Brasília, v. 80, n. 4, pp. 264-90, 2014. Disponível em: <https://juslaboris.tst.jus.br/handle/1939/79452>. Acesso em: 20 set. 2020 .

GADELHA, S. Biopolítica, governamentalidade e educação: introdução e conexões, a partir de Michel Foucault. Belo Horizonte: Autêntica, 2009.

RÜSTOW, A. Das Versagen des Wirtsschaftsliberalismus. Weimar: Metropolis, 2001.

SARDENBERG, C. A. Neoliberal não. Liberal. São Paulo: Globo, 2008.

SENNETT, R. A cultura do novo capitalismo. Tradução de C. Marques. Rio de Janeiro: Record, 2006.

VIRILIO, P. Velocidade e política. Tradução de C. Paciornik. São Paulo: Estação Liberdade, 1996. 